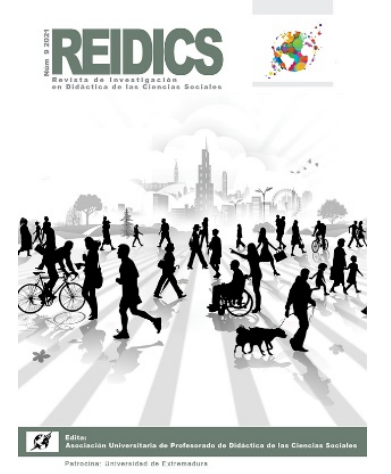

\title{
REIDICS
}

Revista de Investigación en

Didáctica de las Ciencias

Sociales
Núm. 9, 2021

Recibido 08 de junio de 2021

Aceptado 02 de setiembre 2021

E-ISSN: 2531-0968

\section{Educación, patrimonio y turismo: garantía de sostenibilidad}

Convention of the Rights of the Child in Early Childhood Classrooms

Rebeca Guillén Peñafiel

Universidad de Extremadura

Email: rebecagp@unex.es

ORCID: http://orcid.org/0000-0002-9441-0566

Ana María Hernández Carretero

Universidad de Extremadura

Email: ahernand@unex.es

ORCID: http://orcid.org/0000-0003-2412-940X

José Manuel Sánchez Martín

Universidad de Extremadura

Email:jmsanche@unex.es

ORCID: http://orcid.org/0000-0002-4711-3542

DOI: https://doi.org/10.17398/2531-0968.09.254

\section{Resumen}

Uno de los propósitos de la educación patrimonial es concienciar sobre la necesidad de valorar, respetar y proteger el patrimonio. Este mismo compromiso debe orientar la actividad turística, con el fin de reducir sus impactos negativos y contribuir a la sostenibilidad. Considerando el estrecho vínculo que debería establecerse entre educación, patrimonio y turismo, el objetivo de este trabajo es conocer el número de publicaciones científicas que contemplan esta relación como objeto de estudio y cómo la abordan. Para ello, se han revisado revistas de lengua castellana, en su mayoría integradas en la categoría de Educación, con mayor factor de impacto e indexadas en las bases de datos Journal Citation Report y Scopus, entre los años 2000-2018. Igualmente, se han seleccionado los trabajos recogidos en la Web of Science que abarcan esta temática, independientemente de la revista que los publica. Los resultados reflejan la escasa visibilidad que tiene el trinomio educación, patrimonio y turismo en las revistas seleccionadas. Concretamente, la mayoría de los estudios que sí consideran este asunto provienen de revistas latinoamericanas. A partir de estos hallazgos, se realizó un análisis crítico interdisciplinar, que revela la necesidad de integrar estrategias educativas y 
pedagógicas durante las experiencias turísticas, considerándolas un escenario idóneo para su desarrollo. En definitiva, el presente estudio difunde la necesidad de incluir la educación patrimonial en las experiencias de ocio para gestionar la actividad turística de un modo sostenible y, de este modo, contribuir a la conservación de los espacios.

Palabras clave: educación; patrimonio; turismo; sostenibilidad.

\begin{abstract}
One of the purposes of heritage education is to raise awareness about the need to value, respect and protect heritage. This same commitment should guide tourism activity, in order to reduce its negative impacts and contribute to sustainability. Considering the close relationship that should exist among education, heritage and tourism, the objective of this work is to know how many scientific publications contemplate this trinomial as an object of study and how they address this relationship. For this, we have reviewed Spanish language journals, mostly integrated in Education category, with the highest impact factor indexed in Journal Citation Report and Scopus, between 2000-2018. Likewise, we have selected the research collected in the Web of Science that covers this topic, regardless of the journal that publishes them. The results of this analysis reveal the low visibility of the education, heritage and tourism trinomial in the selected journals. Specifically, most of the studies that consider this subject come from Latin American journals. Based on these findings, a critical interdisciplinary analysis was carried out, which reveals the need to integrate educational and pedagogical strategies during tourism experiences, considering them an ideal place for their development. In short, this study disseminates the need to include heritage education in leisure experiences to manage tourism activity in a sustainable way and, thus, contribute to the conservation of spaces.
\end{abstract}

Keywords: education; heritage; tourism; sustainability.

\title{
1. Introducción
}

El turismo cultural es, actualmente, uno de los fenómenos socioeconómicos más potentes a nivel mundial, que ofrece a numerosos países, tanto desarrollados como en vías de desarrollo, buenas perspectivas de crecimiento económico. Asimismo, esta actividad puede contribuir a conocer, comprender y compartir otras manifestaciones culturales, valorar y promocionar la identidad cultural, fomentar la tolerancia y respeto entre los pueblos, incentivar la interculturalidad y estimular la recuperación y conservación de los bienes patrimoniales (González-Varas, 2015).

No obstante, la concepción del turismo desde una visión puramente mercantilista, fundamentada en la masificación y en la generación de estigmas globales, está provocando graves problemas no solo ambientales, sino también socioeconómicos y culturales. Desde los beneficios estrictamente económicos se atenta contra la biodiversidad, se incrementan los desequilibrios económicos y las desigualdades sociales y, lejos de fomentarse la interculturalidad y el respeto por la pluriculturalidad, se homogenizan rasgos y sentimientos, con la consecuente aculturación de la comunidad receptora.

Ante tales amenazas, surge la necesidad de establecer una estrecha relación entre patrimonio y turismo, que quede fuertemente consolidada a través de la educación y que sirva de estímulo para incrementar el conocimiento sobre los bienes patrimoniales y los valores que transmite. De igual modo, esta educación patrimonial servirá para difundir información referida 
a los problemas de degradación y deterioro que afectan a los bienes, a la vez que se generan sentimientos de compromiso y responsabilidad con su conservación y se construyen lazos de identidad.

Numerosas publicaciones científicas hacen referencia exclusiva a la relación entre patrimonio y turismo, mientras que otras se centran en la educación patrimonial. Sin embargo, se considera que los estudios que relacionan estos tres conceptos son aún minoritarios en la literatura científica. Esta es, por tanto, la hipótesis de partida, que da lugar principal objetivo del trabajo: conocer y valorar la representatividad del trinomio "educación, patrimonio y turismo" en la literatura científica, con el fin de impulsar una línea de investigación que aborde esta temática, orientada a promover prácticas turísticas que, desde la educación y la didáctica, estén encaminadas hacia la sostenibilidad. Es decir, fomentar experiencias que faciliten la accesibilidad tanto física como intelectual del público a los bienes patrimoniales para su disfrute, al mismo tiempo que se garantiza su conservación (Ardemagni, 2008). Para ello, se seleccionan y revisan distintas publicaciones de la Web of Science (WOS), así como revistas científicas indexadas en las bases de datos Journal Citation Reports (JCR) y Scopus.

\subsection{La vulnerabilidad del patrimonio}

España cuenta con una enorme riqueza y diversidad patrimonial, lo que la posiciona como uno de los principales destinos turísticos a nivel mundial. Según la UNESCO (2021), el país acoge 49 bienes inscritos en la Lista de Patrimonio Mundial, lo que la sitúa como tercer país en cuanto a bienes declarados, tan solo superado por Italia y China y cuenta con más de 45000 bienes muebles protegidos (Ministerio de Cultura y Deporte, 2021). A este ingente volumen de patrimonio se le añaden diversos espacios naturales, protegidos mediante diferentes figuras. Entre ellos, destacan 16 Parques Nacionales que configuran la Red homónima o la Red Natura 2000, 52 Reservas de la Biosfera y 15 Geoparques declarados por la UNESCO. Pese a esta riqueza, el principal atractivo del país continúa siendo las zonas de playa, según el Ministerio para la Transición Ecológica.

Fruto de esta diversidad de recursos, España fue visitada en 2016 por 75.315 .008 turistas, siguiendo una tendencia creciente hasta 2019, año en el que se alcanzaron los 83509153 turistas internacionales, si bien, ya en 2020, en plena pandemia, descendieron hasta los 18957856 según publica Frontur (INE, 2021). Unas cifras que la sitúan como el segundo país más visitado, a la vez que su aportación al PIB se cifra en 154487 millones de euros para el año 2019, según la Cuenta Satélite de Turismo (INE, 2021). Sin embargo, la gran afluencia de visitantes puede poner en peligro la integridad del patrimonio (Teruel, 2016) y, con ello, las costumbres de la población, que puede verse desposeída de su patrimonio (Cànoves, Villarino y Herrera, 2006).

El World Heritage Centre (2017) ha elaborado una clasificación de las amenazas a las que se expone el patrimonio, según se recoge en "Operational Guidelines for the Implementation of the World Heritage Convention". Entre los riesgos se reconocen la pérdida de la autenticidad histórica o del significado cultural, la disminución de la población de algunas especies causadas por factores humanos, la alteración de los paisajes, la carencia de políticas de conservación, peligros derivados de proyectos de ordenación territorial, planes urbanísticos o la carencia de un plan de gestión. 
Según estas Directrices prácticas de la UNESCO (2017), la acción humana supone un factor de riesgo que ocasiona impactos al patrimonio. La erosión y degradación del entorno, la contaminación, las aguas residuales, la sobreexplotación de recursos, el deterioro del hábitat de especies, el incumplimiento de las normas en espacios protegidos, las edificaciones descontextualizadas o la desculturización del destino, son algunos de los problemas que atentan contra la integridad de los bienes y, con ello, a las raíces culturales de las poblaciones.

Muchos de estos problemas tienen su origen en la forma de concebir y de entender el patrimonio o, lo que es lo mismo, en la escasa valoración que de él se hace. Algunos autores hacen referencia a su concepción como una mercancía, lo que refleja que ciertos elementos patrimoniales son tratados, casi en exclusiva, como recursos económicos destinados a un fin consumista (Gomes, 2000; Prats, 2006; Hernàndez y Martí, 2008). Bajo esta premisa, el patrimonio se convierte en un artículo de compra, vinculado con intereses, sobre todo, comerciales y no tanto sociales o culturales (Quintana y Stagno, 2009). Su valor pasa a ser medido en términos de consumo y del número de turistas que atrae (Prats, 2006), mientras que su valor educativo o simbólico queda en un segundo plano. Tanto es así que existen numerosos estudios científicos centrados en analizar la actividad turística a través de intereses, valoraciones, experiencias o propuestas relacionadas con el incremento económico, el gasto turístico o el desarrollo local (Leno, 1993; Hernández, 2002; Martín, 2003; Grande, 2006; Andrés, 2008; López, 2008; Prats, 2011; Sánchez Peña, 2012), pero ninguno contempla la oferta de actividades didácticas o la difusión de la educación patrimonial como variables que configuran la calidad, el atractivo o potencialidad de un destino desde un punto de vista socioeducativo y cultural. En ellos, no existe ningún indicador para valorar qué se enseña, qué valores y sentimientos se generan en los visitantes, qué aprenden y cómo lo aprenden. Todo ello a pesar de que, según el estudio realizado por ATLAS en 1992 y 1997, sobre más de 14.000 encuestas hechas en Europa, los dos motivos principales para hacer turismo son aprender cosas nuevas y descansar.

Como respuesta a esta situación en la que el patrimonio queda alejado de su valor simbólico y educativo, la UNESCO ha promulgado numerosas Recomendaciones, Directrices y Convenciones con el fin de impulsar su protección. Asimismo, existen otras iniciativas que trabajan en la misma línea, aunque en distintos ámbitos. A nivel europeo se configuran Itinerarios Culturales, la Red de Patrimonio Europeo (HEREIN), Jornadas Europeas de Patrimonio, el Convenio Europeo del Paisaje o el Año Europeo del Patrimonio Cultural. En el panorama nacional se establece la Ley 16/1985, de 25 de junio, del Patrimonio Histórico Español o la Ley 10/2015, de 26 de mayo, para la salvaguardia del Patrimonio Cultural Inmaterial. Igualmente, se crea el Instituto del Patrimonio Cultural de España (IPC) y el Observatorio de Educación Patrimonial en España (OEPE). Por último, a nivel autonómico, existen Decretos y Leyes que contemplan la gestión y protección del patrimonio en cada comunidad.

Considerando la vulnerabilidad del patrimonio, la educación aparece como una herramienta primordial para evitar o paliar los problemas que se derivan de la actividad turística descontrolada. Especialmente porque el turismo, bien gestionado, tiene mucha capacidad para influir positivamente en la conservación del patrimonio, pues posibilita el acceso y la difusión de los elementos patrimoniales, genera recursos económicos para afrontar la gestión patrimonial y 
activa el patrimonio y, por tanto, el desarrollo de las poblaciones donde se encuentra (Troncoso y Almirón, 2005). Por ello, resulta imprescindible impulsar los principios de la educación patrimonial, para contribuir a la mejora de la calidad de los productos turísticos al mismo tiempo que se difunde una toma de conciencia, considerando el desarrollo sostenible como el fin último. De esta forma, el binomio educación y turismo resulta indisociable.

\subsection{Educación patrimonial: premisa para un turismo sostenible}

La educación patrimonial se define como un campo propicio para el conocimiento, valoración y respeto del patrimonio en todas sus manifestaciones, que tiene como fin último la conservación de los referentes culturales, entendidos como señas de identidad de una población. El objetivo de esta educación es intervenir en el proceso de patrimonialización, mediante propuestas educativas que posean conciencia, intencionalidad, estructura, programación y reflexión (Fontal, 2003). Para ello, se basa en el empleo de estrategias que, desde la didáctica, utilizan el patrimonio para concienciar, sensibilizar y generar aprendizajes.

Las investigaciones en torno a la educación patrimonial han aumentado su número, especialmente desde la entrada en el nuevo siglo. Concretamente, el año 2003 supuso un punto de inflexión para esta corriente, que pasa a convertirse en una disciplina científica (Fontal, 2003). Bajo esta línea de investigación aparecen numerosos trabajos que resaltan el valor educativo y didáctico del patrimonio para generar conocimiento, pero sobre todo valores como la identidad, el respeto o la integración cultural (Ishihara-Brito y Rodríguez, 2012; Gutiérrez, 2012; Catalán, 2013; Fontal, 2016; Pinto y Zarbato, 2017; Domínguez y López, 2017; Borghi, 2017; Fontal y Martínez, 2017; Fontal y Marín-Cepeda, 2018).

Igualmente, la educación patrimonial se abre paso entre los estudios enfocados a la educación no formal (Fontal, 2003; Conforti, 2010; Gómez, Calaf y Fontal, 2016; Cuenca, Martín y Schugurensky, 2017, Meunier y Poirier-Vannier, 2017), en especial en aquellos que ponen de manifiesto el protagonismo de los museos como difusores de la memoria colectiva. Algunas conclusiones en este campo manifiestan la necesidad de renovar las estrategias de difusión de muchas instituciones museísticas, que aún cuentan con una comunicación multidireccional y escasas propuestas participativas (Cuenca, Molina-Puche y Martín, 2018).

Otras investigaciones se centran en las experiencias educativas desarrolladas fuera de la escuela (Mendioroz-Lacambra, 2016; Domínguez y López, 2017; Miralles, Gómez y Rodríguez, 2017). Estas actividades garantizan el contacto directo con los referentes patrimoniales, al mismo tiempo que favorecen la unión de los dos ámbitos de enseñanza: el formal y el no formal. A pesar de sus beneficios, algunas investigaciones evidencian que muchas experiencias no estimulan la educación patrimonial (Vasko, 2018). Es por ello que sus principios deben integrarse en todos los contextos de enseñanza, desde las escuelas hasta centros de interpretación, oficinas de turismo, empresas de ocio y cualquier espacio que garantice el acceso al entorno patrimonial, mediante estrategias educativas que apuesten por: a) una educación para todos los niveles y grupos, con actividades reales adaptadas a cada colectivo particular; b) experiencias didácticas que ofrecen aprendizajes vivenciales y sensoriales y no conocimientos teóricos; c) respeto por el patrimonio y el entendimiento de su valor simbólico-identitario; d) el diseño de materiales didácticos e 
interactivos; e) participación en experiencias del patrimonio inmaterial para el conocimiento de las tradiciones y formas de vidas de una determinada comunidad; f) la formación continuada de profesionales, tanto del sector educativo formal (colegios, centros de profesores y recursos) y no formal (museos, centros de interpretación, etc.), como aquellos del sector turístico (empresas de ocio, guías, etc.); y g) promover la colaboración entre el sector educativo y el turístico, orientando sus prácticas al disfrute del patrimonio de una forma sostenible.

Entendida de esta forma, la educación patrimonial se inserta como una pieza clave para la consecución de un turismo sostenible (Geovan, Baptista y Cardozo, 2017). Este queda definido por la Organización Mundial del Turismo como aquel que "tiene plenamente en cuenta las repercusiones actuales y futuras, económicas, sociales y medioambientales para satisfacer las necesidades de los visitantes, de la industria, del entorno y de las comunidades anfitrionas". El turismo, en el marco de la sostenibilidad, se proyectó gracias al Informe Bruntland (1987), alertando que el avance social se estaba llevando a cabo bajo un alto coste medioambiental. Desde entonces, son muchas las declaraciones que han recogido sus principios: Declaración de la Haya (1989); Carta del Turismo Sostenible (1995); Declaración de Québec sobre Ecoturismo (2002), etc. En todas ellas, aparece como nexo común el uso óptimo de los recursos ambientales y el respeto a la autenticidad sociocultural de las comunidades anfitrionas, lo que supone conservar sus referentes patrimoniales y respetar sus valores tradicionales (Cànoves et al., 2006). Unos objetivos de sostenibilidad que solo pueden lograrse si todas las partes implicadas se comprometen en su consecución: sector público, industrias, organizaciones profesionales, empresas privadas y población.

\section{Metodología}

El estudio presenta un análisis bibliográfico que se ha realizado considerando tres pilares que sustentan la investigación y que constituyen un trinomio: educación, patrimonio y turismo. Este punto de partida se justifica debido a la interdependencia que existe entre estas realidades.

En este contexto, el patrimonio se define como un recurso didáctico, es decir, como un elemento capaz de generar lazos afectivos, emocionales y cognitivos con las personas. Bajo esta perspectiva, los bienes patrimoniales presentan una gran carga simbólica e identitaria, pues posibilitan el acceso a la historia, costumbres, tradiciones y formas de vida de distintas comunidades y grupos sociales, además de potenciar valores como el compromiso, la toma de conciencia y el respeto. Por su parte, las prácticas turísticas poseen un gran valor como laboratorios de aprendizaje, puesto que favorecen el contacto directo con los bienes patrimoniales. Además, los mediadores o guías turísticos ejercen una labor de comunicación que posibilita generar discursos adaptados, atractivos y significativos para distintos públicos. Estas cualidades convierten estas experiencias en escenarios óptimos para impulsar la tarea pedagógica. Por último, la educación patrimonial se instala como una disciplina necesaria para desarrollar prácticas turísticas sostenibles, puesto que lo pedagógico se considera como una cualidad intrínseca y necesaria al propio turismo (De Lima, Cappellano y Köche, 2020).

Como se observa, existe una retroalimentación entre los tres conceptos. Esta premisa argumenta el problema de investigación del que parte este estudio: ¿cuál es la situación de la 
educación patrimonial en la literatura y su relación con el turismo? Con la finalidad de conocer la prevalencia de este trinomio en la literatura, en el presente trabajo se analizan distintas bases de datos, revistas y publicaciones científicas de lengua castellana indexadas. Todo ello conforma el siguiente esquema de trabajo (Figura 1):

\section{Figura 1}

\section{Esquema de trabajo}

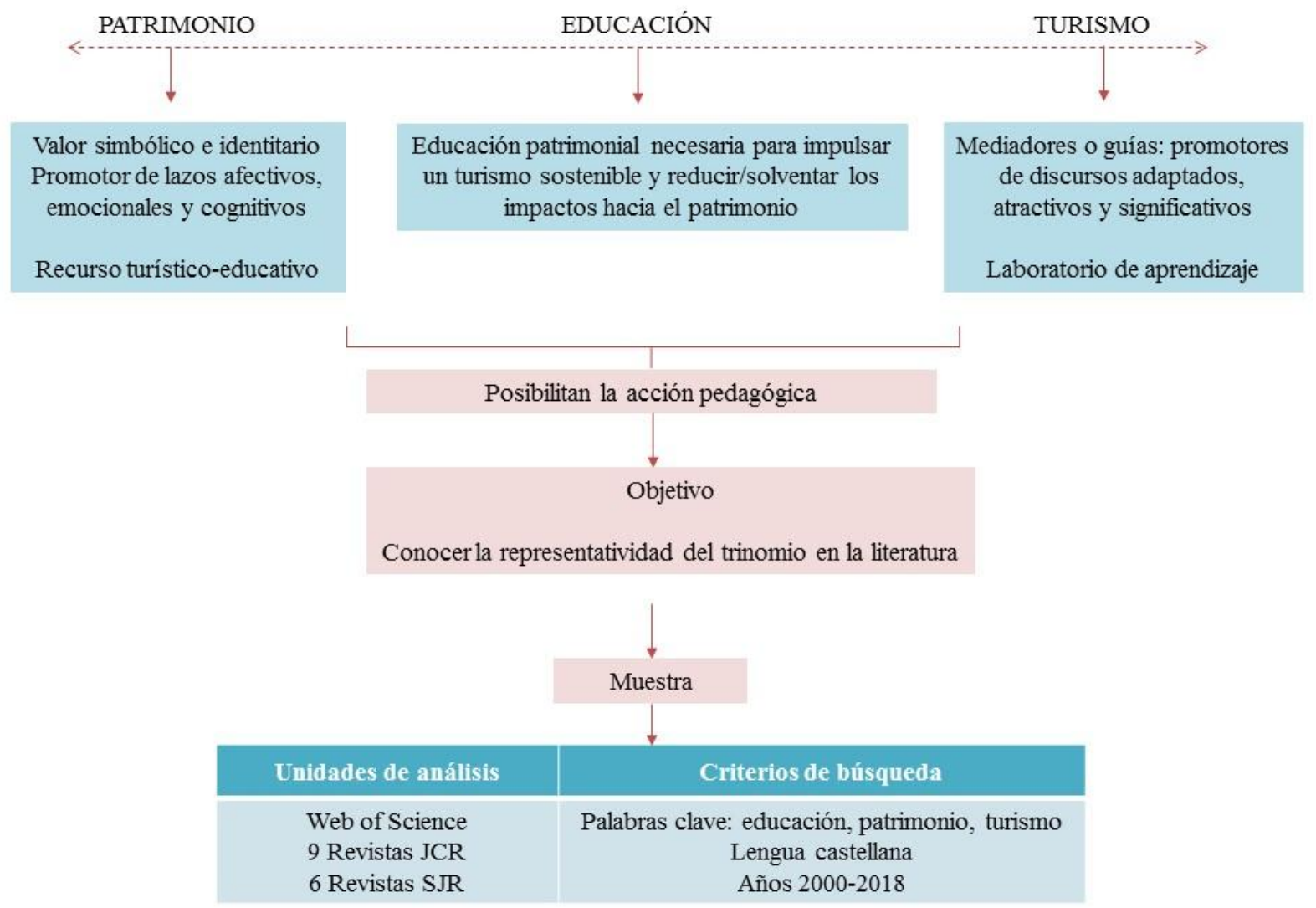

Fuente: elaboración propia

El proceso de búsqueda, selección y análisis sigue una secuencia de trabajo previamente diseñada, que posee tres criterios determinados. 1. Se trata de publicaciones en lengua castellana; 2. Los artículos han sido publicados entre los años 2000 y 2018; y 3. La búsqueda y selección se realiza en función de los tres términos clave: educación, patrimonio, y turismo, que debían encontrarse presentes en el título, palabras clave o resumen de los trabajos. Durante este proceso quedaban excluidos los estudios que solo atendían a dos de los tres conceptos (patrimonio/turismo, patrimonio/educación o educación/turismo), pues el objetivo es conocer cuántos artículos valoran la relación entre estos tres términos y cómo se aborda.

Con base en estas pautas, se examinó la Web of Science y se analizaron las revistas educativas más representativas indexadas en JCR y SJR, adscritas fundamentalmente a la categoría de Educación. No obstante, también se consideraron otras revistas de Geografía, Arte y Turismo, por publicar trabajos relacionados con la temática de estudio. Atendiendo a estas especifidades, 
la búsqueda y análisis se realiza sobre 4 grupos: 1 . Base de datos de la Web of Science; 2 . Revistas indexadas en JCR; 3. Revistas indexadas en SJR; y 4. Revista PASOS (Tabla 1).

\section{Tabla 1}

Unidades de Análisis

\begin{tabular}{|c|c|c|}
\hline Grupo 1 & Base de datos Web of Science & \\
\hline \multirow[t]{9}{*}{ Grupo 2} & Revista & Indexación \\
\hline & Comunicar & JCR (Education) \\
\hline & Revista de psicodidáctica & JCR (Education) \\
\hline & Revista de Educación & JCR (Education) \\
\hline & Educación XXI & JCR (Education) \\
\hline & Enseñanza de las ciencias & JCR (Education) \\
\hline & Revista española de pedagogía & JCR (Education) \\
\hline & Boletín de la AGE & JCR (Geography) \\
\hline & Cultura y educación & JCR (Education) \\
\hline \multirow{6}{*}{ Grupo 3} & Estudios sobre educación & SJR (Education) \\
\hline & Infancia y aprendizaje & SJR (Education) \\
\hline & Profesorado & SJR (Education) \\
\hline & Revista complutense de educación & SJR (Education) \\
\hline & Revista de investigación educativa & SJR (Education) \\
\hline & Arte, individuo y sociedad & SJR (Visual Arts and Performing Arts) \\
\hline Grupo 4 & $\begin{array}{l}\text { PASOS. Revista de turismo y patrimonio } \\
\text { cultural }\end{array}$ & JCR (Hospitality, Leisure, Sport, Tourism) \\
\hline
\end{tabular}

Fuente: Elaboración propia

\section{Resultados}

Los resultados reflejan una escasa presencia de trabajos científicos que relacionan educación, patrimonio y turismo. El número de publicaciones que contempla esta línea de estudio durante el período 2000-2018 es muy bajo, a pesar de la influencia recíproca entre las tres realidades. Únicamente se han encontrado un total de 12 artículos que abordan esta cuestión. Esto supone un número muy bajo si se compara con el volumen de estudios que relacionan dos de los tres conceptos (Tabla 2).

Esta tabla muestra la prevalencia del trinomio educación, patrimonio y turismo en la literatura científica, según el número de publicaciones registradas en cada grupo que contempla esta línea de investigación. Como se aprecia, además de su escasa e incluso nula representatividad en cada uno de los grupos, cabe resaltar que la cantidad de trabajos publicados en relación con los binomios educación y patrimonio o patrimonio y turismo es mucho mayor que aquellos centrados en educación/turismo, cuya presencia es inexistente en las revistas JCR y SJR analizadas. Esto sugiere que el vínculo entre el ámbito educativo y turístico aún no está suficientemente asentado en la literatura. 
Tabla 2

Número de trabajos que contemplan el trinomio educación, patrimonio y turismo

\begin{tabular}{llcccc}
\hline Grupo & \multicolumn{1}{c}{ Unidad de análisis } & AEP & AET & APT & AEPT \\
\hline $\mathbf{1}$ & Web of Science & $\mathbf{1 1 7}$ & $\mathbf{7 2}$ & $\mathbf{2 1 6}$ & $\mathbf{9}$ \\
\cline { 2 - 6 } & Revistas & & & & - \\
& Comunicar & 1 & - & - & - \\
& Revista de Psicodidáctica & - & - & - & - \\
& Revista de Educación & 9 & - & - & - \\
& Educación XXI & - & - & - & - \\
& Enseñanza de las Ciencias & - & - & - & - \\
& Revista Española de Pedagogía & - & - & - & - \\
& Cultura y Educación & 4 & - & - & - \\
\hline $\mathbf{3}$ & Boletín de la AGE & 2 & - & 12 & - \\
& Estudios sobre Educación & - & - & - & - \\
& Infancia y Aprendizaje & - & - & - & - \\
& Profesorado & 1 & - & - & - \\
& Revista complutense de Educación & 5 & - & - & - \\
& Revista de Investigación Educativa & - & - & - & - \\
\hline $\mathbf{4}$ & Arte, individuo y sociedad & 9 & - & 1 & $\mathbf{0}$ \\
\hline Total & Subtotal & $\mathbf{3 1}$ & $\mathbf{0}$ & $\mathbf{1 3}$ & $\mathbf{8 9}$ \\
\hline PASOS. Revista de Turismo y Patrimonio Cultural & $\mathbf{1 1}$ & $\mathbf{7}$ & $\mathbf{3 9}$ \\
\hline
\end{tabular}

AEP: artículos sobre educación y patrimonio; AET: artículos sobre educación y turismo; APT: artículos sobre patrimonio y turismo; AEPT: artículos sobre educación, patrimonio y turismo.

En lo referente al Grupo 1, compuesto por los artículos indexados en WOS, se recogen únicamente 9 trabajos que relacionan estos tres conceptos, lo cual supone un número muy escaso si se compara con aquellos que contemplan dos de las tres realidades (Tabla 3).

Es destacable que todos estos artículos han sido publicados en revistas iberoamericanas, concretamente de Argentina, Venezuela, Brasil, México, Chile y Cuba, pero ninguno en revistas españolas. En cuanto al campo de conocimiento, las publicaciones pertenecen sobre todo al ámbito de las Ciencias Sociales, Antropología y Humanidades, mientras que, en el campo de la Educación, apenas se aborda la interrelación entre estos tres conceptos. Asimismo, parece interesante señalar que todos los trabajos aparecen publicados a partir del año $2010 \mathrm{y}$, principalmente, entre 2017 y 2018. De estos datos se desprende que se trata de una línea de trabajo reciente.

En el segundo y tercer grupo se recogen ocho revistas indexadas en JCR y seis revistas con factor de impacto en SJR. A pesar de la variedad de revistas seleccionadas, ninguna de ellas incorpora ninguna publicación relativa al trinomio. Entre los hallazgos, cabe señalar que existen diferencias en cuanto al volumen de trabajos que contemplan dos de las tres realidades. En relación con ello, se registra un mayor número de publicaciones sobre educación y patrimonio, seguidas de aquellas que se orientan al estudio de patrimonio y turismo y, finalmente, las que se centran en el binomio educación y turismo, para las que no se ha encontrado ningún resultado. 
Tabla 3

Artículos de la Web of Science que abordan la relación entre educación, patrimonio y turismo

\begin{tabular}{|c|c|c|c|c|}
\hline Artículo & Revista & Año & Área de investigación & País \\
\hline $\begin{array}{l}\text { Turismo cultural como } \\
\text { experiencia educativa de ocio }\end{array}$ & $\begin{array}{l}\text { Polis, Revista } \\
\text { latinoamericana }\end{array}$ & 2010 & Sociología & Chile \\
\hline $\begin{array}{l}\text { Jóvenes resignificando } \\
\text { patrimonios: análisis de una } \\
\text { experiencia escolar en la ciudad } \\
\text { de Olavarría }\end{array}$ & $\begin{array}{l}\text { Espacios en } \\
\text { blanco, serie } \\
\text { indagaciones }\end{array}$ & 2014 & Artes y Humanidades & Argentina \\
\hline $\begin{array}{l}\text { Los senderos transitados: una } \\
\text { mirada al estado del arte de la } \\
\text { interpretación ambiental en } \\
\text { Venezuela entre } 2000 \text { y } 2015\end{array}$ & $\begin{array}{l}\text { Revista de } \\
\text { investigación }\end{array}$ & 2016 & $\begin{array}{l}\text { Educación e } \\
\text { Investigación } \\
\text { Educativa; Artes y } \\
\text { Humanidades } \\
\end{array}$ & Venezuela \\
\hline $\begin{array}{l}\text { Educación, restauración y } \\
\text { turismo: una reflexión dialéctica } \\
\text { aplicada a la Casa Sede de la } \\
\text { Hacienda Forestal (Irati, Brasil) }\end{array}$ & $\begin{array}{l}\text { Estudios y } \\
\text { perspectivas en } \\
\text { turismo }\end{array}$ & 2017 & Ciencias Sociales & Brasil \\
\hline $\begin{array}{l}\text { Educación en gastronomía: su } \\
\text { vínculo con la identidad cultural y } \\
\text { el turismo }\end{array}$ & $\begin{array}{l}\text { El periplo } \\
\text { sustentable }\end{array}$ & 2017 & $\begin{array}{l}\text { Ciencias } \\
\text { Medioambientales y } \\
\text { ecología; Ciencias } \\
\text { sociales } \\
\end{array}$ & México \\
\hline $\begin{array}{l}\text { Turismo rural desde la educación } \\
\text { popular. Experiencia en la vega } \\
\text { tabacalera "Hoyo de Mena", Pinar } \\
\text { del Río, Cuba }\end{array}$ & $\begin{array}{l}\text { Revista Estudios } \\
\text { del Desarrollo } \\
\text { Social: Cuba y } \\
\text { América Latina }\end{array}$ & 2017 & Ciencias Sociales & Cuba \\
\hline $\begin{array}{l}\text { Estrategia de gestión pública para } \\
\text { un enoturismo sustentable a } \\
\text { partir de la percepción de } \\
\text { problemas ambientales: El Valle } \\
\text { de Guadalupe (México) }\end{array}$ & $\begin{array}{l}\text { Estudios y } \\
\text { perspectivas en } \\
\text { turismo }\end{array}$ & 2018 & Ciencias Sociales & México \\
\hline $\begin{array}{l}\text { Sumergidos con lupa en los ríos } \\
\text { del Cabo de Hornos: valoración } \\
\text { ética de los ecosistemas } \\
\text { dulceacuícolas y sus co-habitantes }\end{array}$ & $\begin{array}{l}\text { Magallania } \\
\text { (Punta Arenas) }\end{array}$ & 2018 & Antropología & Chile \\
\hline $\begin{array}{l}\text { Más allá de la arqueología } \\
\text { académica: conversando con los } \\
\text { guías comunitarios de Uaxactún }\end{array}$ & $\begin{array}{l}\text { Estudios de } \\
\text { cultra maya }\end{array}$ & 2018 & $\begin{array}{l}\text { Antropología, } \\
\text { arqueología }\end{array}$ & México \\
\hline
\end{tabular}

Fuente: elaboración propia

Finalmente, la revista PASOS, único ejemplo del grupo 4, integra tres trabajos que abordan el trinomio educación, patrimonio y turismo (Tabla 4).

Sin embargo, porcentualmente, la presencia del trinomio es testimonial, pues la gran mayoría de los trabajos contempla, sobre todo, cuestiones sobre patrimonio y turismo. En este caso, la presencia de trabajos orientados al estudio del binomio educación y patrimonio o educación y turismo es mucho menor.

En definitiva, tras la revisión de un total de 14 revistas indexadas en bases de datos con alto factor de impacto, se constata que no hay un solo trabajo publicado que aborde la relación educación, patrimonio y turismo. Se han encontrado ejemplos de esta conexión en algunas publicaciones recogidas en la Web of Science y en la revista PASOS. Con base en estos resultados, llama la atención la ausencia de trabajos que relacionan estos tres conceptos en las revistas del campo educacional. Ante esta realidad surgen algunas dudas, tales como: ¿es que acaso la educación no es consciente de que la actividad turística debe estar regulada por principios de 
sostenibilidad que minimicen las posibles amenazas y potencien los beneficios?; ¿no es aconsejable extrapolar la educación patrimonial fuera de las aulas?; ¿no ofrecen las visitas, guías o cualquier actividad turística una excelente oportunidad para educar en patrimonio? o ¿no deberían las empresas del sector turístico fomentar la educación patrimonial?

\section{Tabla 4}

Artículos publicados en PASOS que abordan la relación entre educación, patrimonio y turismo

\begin{tabular}{lll}
\hline Artículo & Año & Indexación \\
\hline $\begin{array}{l}\text { Educación turística - reflexiones para la elaboración de una propuesta con } \\
\text { base en la cultura }\end{array}$ & 2010 & IN RECS \\
$\begin{array}{l}\text { Turismo y sitios arqueológicos en Las Islas Shetland del Sur, Antártida } \\
\text { ¿Sueño o pesadilla en Mallorca? Un proyecto pedagógico interdisciplinario }\end{array}$ & 2018 \\
adecuado a la cultura de ocio y diversión & & \\
\hline
\end{tabular}

Fuente: Elaboración propia.

\section{Análisis y discusión}

Tras examinar los 12 artículos que abordan el nexo entre educación, patrimonio y turismo, se aprecia que todos ellos presentan un rasgo común: plantean la necesidad de integrar modelos, experiencias, programas, proyectos o prácticas educativas como herramientas para favorecer un turismo sustentable. De su análisis y de su contraste con otros trabajos, se recogen varias ideas que ponen de manifiesto la interdependencia entre estas realidades y que resaltan la relevancia de asociar estos tres campos de estudio (Figura 2).

\section{Figura 2}

Esquema resumen: relación entre turismo y educación patrimonial

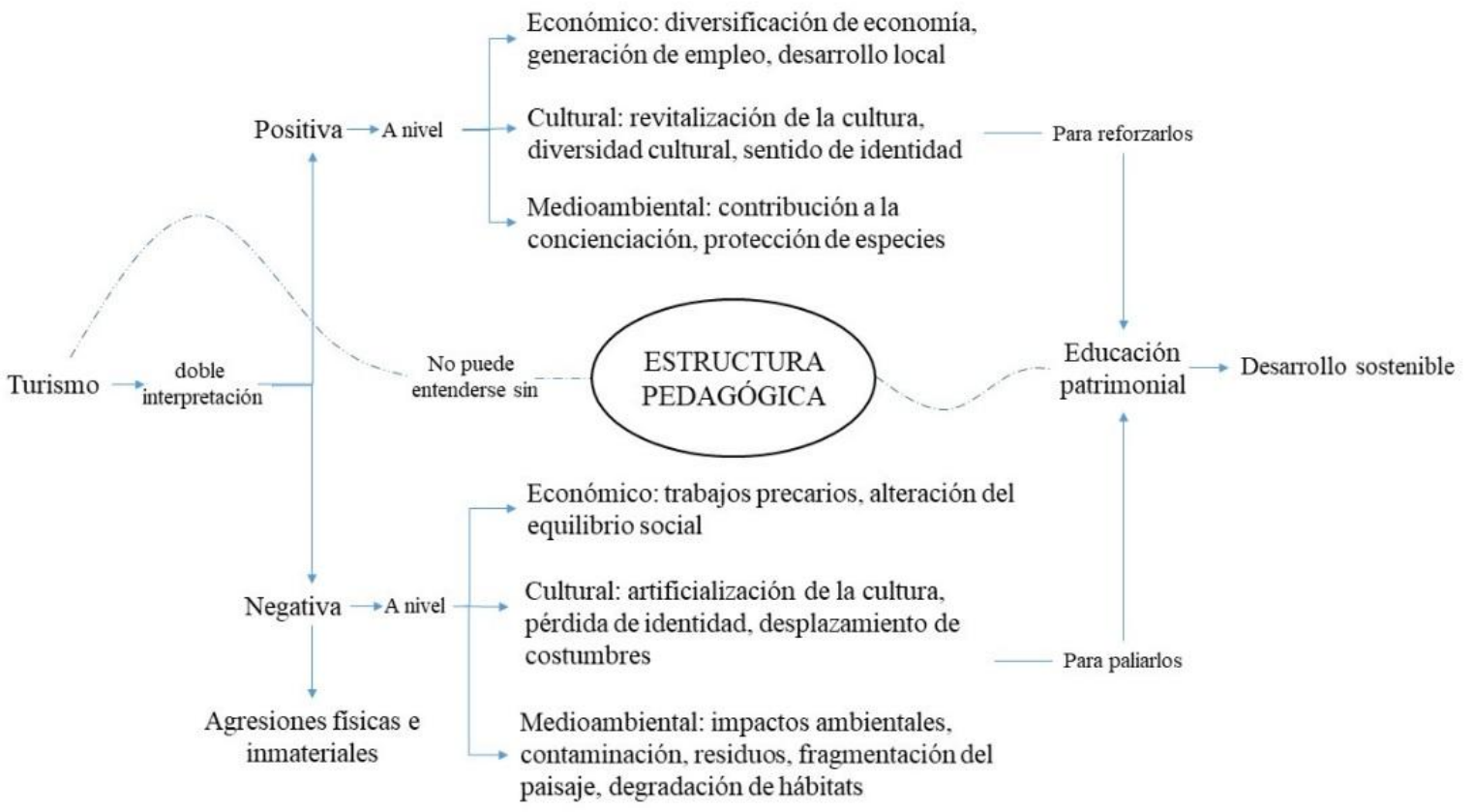

Fuente: Elaboración propia 
Primeramente, existen opiniones diversas sobre el fenómeno del turismo. Los estudios evidencian que aquellas personas implicadas en mayor medida en esta actividad realizan una valoración más positiva sobre ella que aquellos que están al margen, los cuales se muestran más ambivalentes e incluso contrarios (Hall, Roberts y Mitchell, 2017). Considerando esta dualidad, la relación entre el turismo y el patrimonio siempre ha sido delicada. Por un lado, se critica el empleo del patrimonio como un simple generador de recursos económicos, mientras que, por otro, se observa la necesidad del patrimonio para generar turismo y de este para preservar el patrimonio, afirmando que uno sin el otro no puede mantenerse (Geovan et al., 2017). Fruto de este doble posicionamiento, se reconocen ventajas y se advierten posibles amenazas derivadas del turismo.

Comenzando por los aspectos positivos, desde un punto de vista cultural, el turismo bien gestionado puede revitalizar y recuperar la cultura local, potenciar el sentido de identidad, fomentar la diversidad cultural, integrar el diálogo entre civilizaciones, desarrollar actividades colectivas e impulsar el reconocimiento del lugar (Hernández, Moroño y Guillén, 2021). A nivel socioeconómico, permite diversificar las economías rurales, a la vez que promueve actividades innovadoras, genera empleo, reduce el éxodo, contribuye al desarrollo local y posibilita la generación de recursos para la conservación (Cànoves et al., 2006). Por último, a nivel medioambiental, permite revitalizar los recursos naturales, lo que puede contribuir a la concienciación patrimonial y medioambiental o favorecer la protección de espacios rurales (Valderrama, Meraz, Velázquez y Flores, 2012).

Sin embargo, para alcanzar estos beneficios, el turismo siempre debe llevar implícita una clara estructura pedagógica (Orduna y Urpí, 2010). Por otra parte, los problemas derivados de la práctica turística son evidentes. Entre ellos destacan la artificialización de la cultura local, con la consecuente desculturización del destino, pérdida de identidad, una alteración del equilibrio social, aculturación de la población receptora, generación de impactos ambientales, de polución, residuos y contaminación, fragmentación o degradación del paisaje, alteración de los hábitats locales de fauna y flora o fomento de puestos de trabajo precarios (Cànoves et al., 2006; Orduna y Urpí, 2010; da Silva Fonseca, 2010; Reyes, Olague y Verján, 2018). En este sentido, se contemplan tanto agresiones físicas al patrimonio y a su entorno como a la cultura inmaterial, banalizando las costumbres y tradiciones de las poblaciones locales (Choay, 2011; Brusadin y da Silva, 2015; Geovan et al., 2017). Unos problemas que tienen su origen en la falta de valorización del patrimonio y que generan impactos a nivel social, económico y cultural (Reyes et al., 2018; Ximena, 2018).

Otras veces, el origen de estos problemas reside en el desarrollo de prácticas turísticas producto de una sociedad capitalista (Funari y Pinsky, 2003), donde el motivo del viaje muchas veces tiene más relación con el poder adquisitivo y las posibilidades económicas que con el gusto por la historia, el arte o el interés por aprender. Esto, a su vez, repercute en la forma en la que el visitante se comporta frente a los bienes y a la cultura local. Se trata de turistas que no son totalmente conscientes de la importancia de los referentes patrimoniales, lo que, fruto de su despreocupación, contribuye, de manera paulatina, a su falta de valorización, al abandono o su degradación. 
Frente a estas tensiones, la educación patrimonial es una premisa indispensable para gestionar la actividad turística de forma sostenible. Tiene por objetivo la valoración del patrimonio como fuente de saber, la difusión de una conciencia conservacionista, sensibilizar al visitante y a la comunidad sobre la importancia de preservarlo y la concepción del turismo con una actividad que no puede entenderse sin una estructura pedagógica (Figueira, 2007; Orduna y Urpí, 2010; Geovan, et al., 2017).

Se define como una herramienta que puede ser utilizada en un proceso conciliador entre patrimonio y turismo, utilizando los bienes culturales como recursos para impulsar la tarea pedagógica (Grunberg, 2014). Este modelo de educación permite, del mismo modo, conocer la cultura de un pueblo e insertarla en un contexto determinado, teniendo como finalidad última la valoración propia de su identidad. Se enfoca a la concienciación de los visitantes y de la propia comunidad, lo cual resulta importante para que comprendan a fondo su existencia, desde sus orígenes hasta la actualidad, así como para reforzar su identidad y sentido de pertenencia (Geovan et al., 2017). De esta forma, la propia población buscará preservarlo y esa perspectiva se transmitirá a los visitantes, ya no solo por las instituciones culturales y educativas encargadas de hacerlo, sino también por la propia población autóctona. Se trata de una tarea educativa que aparece implícita en el discurso de cualquier persona que difunda el patrimonio.

Extender la educación patrimonial al conjunto de la sociedad requiere emplear actividades que creen un sentimiento de valoración (Darías, Pérez y Ramírez, 2017), impulsando la adquisición de actitudes de respeto. Por ello, surge la interpretación patrimonial, como una experiencia lúdica y educativa que revela significados de los bienes patrimoniales por medio del contacto directo (Tilden, 2009; Blockley y Hems, 2013). Se trata de una disciplina que ha evolucionado con el tiempo. En sus orígenes, aparecía suscrita a espacios naturales protegidos, mientras que en la actualidad su visión está más cercana a la interpretación de "los patrimonios" (Giacomasso, Mariano y Conforti, 2014), abarcando multitud de campos de actuación. Este proceso de interpretación no puede desligarse ni de las prácticas turísticas ni de los profesionales de este sector (Moncada, Aranguren y Pellegrini, 2016), por lo que la educación patrimonial, es una tarea pedagógica que debe estar presente en los profesionales del turismo.

Este proceso de interpretación se define como una acción educativa ambiental (Contador et al., 2018), que requiere proporcionar un discurso adaptado a un público, sea o no especializado. Se asienta en el constructivismo como estrategia pedagógica, puesto que trata de despertar la curiosidad y fomentar la participación. Bajo esta definición, como acción educativa, el profesional del turismo debe conocer estrategias didácticas para desarrollarla. Este, precisamente, es el punto de unión entre la educación patrimonial y el turismo. Sumado a ello, varios estudios han revelado la efectividad educativa de las visitas guiadas (Pellegrini, 2009; Moncada et al., 2016). Igualmente, esta disciplina contribuye a controlar los impactos negativos del turismo (Morales, 2001).

Bajo esta concepción educativa que debe impregnar la labor turística y a las instituciones culturales, se va perfilando cada vez más la figura del educador patrimonial (Fontal, 2003), con un perfil que posee necesidades formativas y de sensibilización para generar experiencias que favorezcan una toma de conciencia (Orduna y Urpí, 2010). Se trata de una persona que debe tener una formación sólida tanto en metodologías educativas como en disciplinas culturales: "no es 
posible pretender que exista un educador patrimonial muy cualificado en el dominio de conocimientos vinculados a la cultura si desconoce la realidad educativa" (Fontal, 2003, p. 201).

Por tanto, este profesional turístico, preparado en educación patrimonial debe poseer una doble competencia: técnica y pedagógica (Orduna y Urpí, 2010). La primera referida a las peculiaridades e intrahistoria del recurso patrimonial, lo que supone dominar conocimientos de historia, arte, geografía, antropología o sociología. La segunda, referida a su habilidad para promover acciones educativas encaminadas a la sensibilización. Existen varias formas didácticas de exponer los recursos: visitas guiadas, teatralizaciones o escenificaciones, exposiciones, visitas a centros de interpretación o museos, montajes con música, uso de tecnologías, narración de un episodio de cultura intangible que despierte curiosidad, etc. Para que esta experiencia didáctica sea gratificante es necesario implicar activamente al turista, no solo haciéndole escuchar, sino generándole sensaciones derivadas de tocar, sentir, oler, degustar, participar (Orduna y Urpí, 2010).

Por otra parte, existe una gran variedad de públicos con características físicas y psicológicas distintas. Por ello, este profesional debe poseer unos conocimientos mínimos de psicología para adaptar su lenguaje y su propuesta de actividades a las características del grupo. Para generar una experiencia educativa, debe proponerse conocer cuál es el interés fundamental de su público, cuáles son sus aspiraciones, intereses y motivaciones, hechos que solo pueden hacerse escuchando (Escarbajal, 1992). En este sentido, al hablar de educador patrimonial, nos acercamos a un perfil académico interdisciplinar, que debe reunir conocimientos sobre la realidad cultural y natural que difunde, pero también habilidades didácticas, relacionadas con su capacidad de interactuar, de escuchar o de analizar las características de su grupo.

Ante tales afirmaciones, recogidas en diversos trabajos de investigación, resultan evidentes las posibilidades educativas de la actividad turística. Para ello, el turismo necesita ser trabajado de forma que favorezca la conservación del patrimonio, y, consecuentemente, refuerce el autoconocimiento de las sociedades sobre su valor (Ximena, 2018). "Un comportamiento preservacionista que sólo será construido por medio de la educación" (da Silva Fonseca, 2010, p.68). No se debe olvidar que el incremento de esta cultura de ocio genera fuentes de trabajo y recursos económicos, pero también alteraciones ambientales, por lo que se debe buscar un modelo de educación patrimonial encaminado hacia el desarrollo sostenible a partir de una toma de conciencia (Otto, 2007).

A pesar de ese claro vínculo entre la educación patrimonial y el turismo, varios autores resaltan la dificultad de enlazar en la práctica estas realidades y enfatizan sobre la dificultad que existe para alcanzar un desarrollo sostenible (Orduna y Urpí, 2010; Martín y Martín Gil, 2016; Moncada et al., 2016). Las conclusiones de sus estudios dictaminan que a medida que avanza la cultura, elementos patrimoniales nuevos sustituyen a los bienes antiguos, a no ser que este sea considerado útil en el contexto mercantil. Esto supone primar las ganancias económicas y considerar el valor social y cultural en segundo lugar. Por ello, afirma que el turismo como factor pedagógico es utópico e irreal (Choay, 2011), pues no existen inversiones con un exclusivo interés cultural, sin retorno económico (Geovan et al., 2017). 
Desde esta estrecha relación entre educación, patrimonio y turismo y teniendo en cuenta las dificultades para integrarlas en la práctica, se insiste en la necesidad de fundamentar la gestión de la actividad turística desde la educación patrimonial.

\section{Conclusiones}

Las principales conclusiones que se obtienen tras el estudio se centran en valorar la prevalencia del trinomio educación, patrimonio y turismo en la literatura científica y en analizar cómo se aborda este vínculo.

En primer lugar, se ha comprobado que el trinomio educación, patrimonio y turismo es una realidad que aún tiene insuficiente peso en publicaciones científicas. Únicamente se han encontrado 12 artículos que hacen referencia a la interrelación entre estos tres conceptos. Más concretamente, estos proceden de publicaciones de la Web of Science y de la Revista Pasos. Esto supone que no se ha registrado ningún estudio interesado en esta línea de trabajo entre las revistas educativas con mayor índice de impacto indexadas en JCR y Scopus.

En segundo lugar, la mayoría de los trabajos que responden al objetivo de esta investigación siguen una misma dinámica: principalmente se trata de estudios procedentes de países latinoamericanos y pertenecen a revistas adscritas a una categoría distinta a la Educación. Especialmente se enmarcan dentro de las pertenecientes a las Ciencias Sociales, Antropología, Arte y Humanidades. Además, son investigaciones publicadas primordialmente entre los años 2017 y 2018. Bajo este descubrimiento, se reconocen dos realidades. Por un lado, que las revistas educativas españolas parecen mostrar escaso interés hacia esta línea de trabajo. Por otro, que se trata de un campo de investigación emergente, que pretende adquirir relevancia en estos últimos años. En tercer y último lugar, si bien la representatividad del trinomio educación, patrimonio y turismo es testimonial entre los grupos analizados, también lo es la del binomio educación y turismo. En relación con esta idea, se ha detectado que el número de trabajos que asocian educación y patrimonio, así como patrimonio y turismo, resulta significativamente mayor que aquellos que relacionan el ámbito educativo con el turístico. Ante ello, se presupone que el indudable vínculo que existe entre la educación y el turismo aún no posee suficiente relevancia, a pesar de la necesidad de enlazar estas dos realidades para garantizar prácticas turísticas sostenibles.

Atendiendo a los objetivos marcados en este estudio, los resultados constatan la escasa presencia del trinomio educación, patrimonio y turismo en las publicaciones científicas. Esto supone que las investigaciones no valoran suficientemente las conexiones entre estos tres campos de conocimiento. En definitiva, se concluye que la idea ya constatada de que la educación patrimonial resulta una premisa indispensable para garantizar un turismo sostenible aún no está suficientemente enraizada. Es decir, aún se está lejos de integrar la educación patrimonial en la gestión, organización y promoción de la actividad turística.

La originalidad del estudio reside en ilustrar la poca importancia que en las publicaciones científicas se le viene dando, hasta ahora, a la relación que debe existir entre educación, patrimonio y turismo y a reivindicar su necesidad, dada la clara interrelación existente entre todos los términos. Ello a pesar de que esta interconexión es perfectamente visible y coherente para 
todos los campos. En este sentido, el interés principal de este trabajo es fomentar el desarrollo de estrategias educativas entre la educación formal, no formal e informal que deben dirigirse a formar a profesionales capacitados para desarrollar propuestas turísticas y pedagógicas que partan desde y para la educación patrimonial. Asimismo, persigue concienciar tanto a empresas del sector turístico, como a administraciones y emprendedores, de la necesidad de fomentar la educación patrimonial, pues, desde sus planteamientos se lograrán experiencias singulares, amenas y divertidas que atraerán un mayor número de turistas que, además, serán más respetuosos con los bienes patrimoniales y con las culturas que representan. Por ello, este trabajo persigue impulsar una línea de investigación destinada a indagar acerca de la importancia de promover la educación patrimonial en las experiencias turísticas.

No obstante, este estudio posee limitaciones. Entre ellas destaca que se han analizado revistas con alto factor de impacto, en castellano, y se partió de su inclusión en la categoría Educación. Por ello, un objetivo de investigación futura podría ser contemplar, debido a los resultados obtenidos, la presencia del trinomio en revistas escritas en lengua inglesa y analizar un mayor número de revistas que contemplen categorías complementarias a la educación. A pesar de estas limitaciones, este estudio es el primero en evaluar la presencia del nexo educaciónturismo-patrimonio en las publicaciones científicas, además de ser uno de los pocos centrados en esta línea de investigación.

\section{Agradecimientos}

Esta publicación se encuadra dentro de las investigaciones llevadas a cabo durante la ejecución del proyecto "Diseño y elaboración de productos estratégicos diferenciados para la potenciación del turismo rural en Extremadura. De la detección de problemas a la propuesta de soluciones basadas en criterios geoestadísticos", cuya clave es IB 16040, y se encuentra financiado por la Consejería de Economía e Infraestructuras de la Junta de Extremadura y por el Fondo Europeo de Desarrollo Regional (FEDER); también ha sido financiando por la Junta de Extremadura y el Fondo Social Europeo: una forma de hacer Europa, a través de la "Financiación de contratos predoctorales para la formación de Doctores en los centros públicos de I+D pertenecientes al Sistema Extremeño de Ciencia, Tecnología e Innovación". Expediente PD16025. Además, ha recibido Financiación del Fondo Europeo de Desarrollo Regional (FEDER) y por la Junta de Extremadura (España) al Grupo de Investigación DESOSTE, a través de la referencia de ayuda GR-18052, y al Grupo de Investigación SEJ036, a través de la ayuda GR-18026.

\section{Referencias bibliográficas}

Andrés, J. L. (2008). Evaluación del potencial turístico en espacios rurales. En F. Cebrián (coord.). Turismo y desarrollo local (pp. 153-160). Sevilla: Secretariado de publicaciones de la Universidad de Sevilla.

Ardemagni, M. (2008). El público y la conservación del patrimonio. En Santos Mateos (coord.). La comunicación global del patrimonio cultural (pp. 111-132). Gijón: Trea.

Cànoves, G., Villarino, M., y Herrera, L. (2006). Políticas públicas, turismo rural y sostenibilidad. Boletín de la Asociación de Geógrafos Españoles, 41, 199-220. Recuperado de https://bage.age-geografia.es/ojs//index.php/bage/article/viewFile/1990/1903 
Blockley, M., y Hems, A. (2013). Heritage interpretation. London: Routledge.

Borghi, B. (2017). Ecomuseos y mapas de comunidad: un recurso para la enseñanza de la historia y el patrimonio. Estudios pedagógicos (Valdivia),43(4), 251-275. Recuperado de https://scielo.conicyt.cl/pdf/estped/v43n4/art13.pdf

Brusadin, L., y da Silva, R. H. (2015). O uso turístico do patrimônio cultural em Ouro Preto. CULTUR-Revista de Cultura e Turismo, 6(1), 69-89. Recuperado de http://each.usp.br/turismo/publicacoesdeturismo/ref.php?id=25526

Catalán, R. (2013). Prácticas y discursos pedagógicos en Toconao: Cultura, patrimonio e interclturalidad. Estudios atacameños, 45,19-40. Recuperado de https://scielo.conicyt.cl/pdf/eatacam/n45/art03.pdf

Choay, F. (2011). A alegoria do patrimônio. São Paulo: Unesp.

Conforti, M. E. (2010). Educación no formal y patrimonio arqueológico: Su articulación y conceptualización. Intersecciones en antropología, 11(1), 103-114. Recuperado de https://www.redalyc.org/articulo.oa?id=179515632008

Contador, T., Rozzi, R., Kennedy, J., Massardo, F., Ojeda, J., Caballero, P., ... y Lazzarino, S. (2018). Sumergidos con lupa en los ríos del cabo de hornos: Valoración ética de los ecosistemas dulceacuícolas y sus co-habitantes. Magallania (Punta Arenas), 46(1), 183-206. Recuperado de

https://scielo.conicyt.cl/scielo.php?script=sci_arttext\&pid=S0718-

\section{3}

Cuenca, J. M., Martín, M., y Schugurensky, D. (2017). Educación para la ciudadanía e identidad en los museos de Estados Unidos: Análisis desde la perspectiva de la educación patrimonial. Estudios pedagógicos (Valdivia), 43(4), 29-48. Recuperado de https://scielo.conicyt.cl/scielo.php?script=sci_arttext\&pid=S0718-07052017000400002

Cuenca, J. M., Molina-Puche, S., y Martín, M. (2018). Identidad, ciudadanía y patrimonio. Análisis comparativo de su tratamiento didáctico en museos de Estados Unidos y España. Arbor, 194(788), $447 . \quad$ Recuperado de http://arbor.revistas.csic.es/index.php/arbor/article/view/2260

Darías, M., Pérez, M. D. L. A., y Ramírez, J. F. (2017). Turismo rural desde la Educación Popular. Experiencia en la vega tabacalera" Hoyo de Mena", Pinar del Río, Cuba. Revista Estudios del Desarrollo Social: Cuba y América Latina, 5(2), 52-59. Recuperado de http://scielo.sld.cu/scielo.php?script=sci_arttext\&pid=S2308-01322017000200006

De Lima, F., dos Santos, M. M. C., y Köche, J. C. (2020). Turismo pedagógico ou Atividade pedagógica pelo turismo? O binômio «turismo pedagógico»: concepções de turismo e pressupostos epistemológico-pedagógicos subjacentes. Investigaciones Turísticas, 19, 139-162. Recuperado de http://rua.ua.es/dspace/handle/10045/106754

da Silva Fonseca, A. (2010). Educación turística-reflexiones para la elaboración de una propuesta con base en la cultura. PASOS. Revista de Turismo y Patrimonio Cultural, 8(1), 61-69. Recuperado de http://www.pasosonline.org/Publicados/8110/PS0110_5.pdf

Domínguez, A., y López, R. (2017). Patrimonios en conflicto, competencias cívicas y formación profesional en educación primaria. Revista de Educación, 375, 86-109. Recuperado de https://minerva.usc.es/xmlui/handle/10347/15805 
Escarbajal, A. (1991). El desarrollo comunitario como nuevo horizonte educativo. Pedagogía social: revista interuniversitaria, 7, 7-18. Recuperado de https://dialnet.unirioja.es/servlet/articulo?codigo $=2541878$

Figueira, G. K. (2007). A educação patrimonial (cultural) e o desenvolvimento sustentável do turismo. Brasília: Universidade de Brasília.

Fontal, 0. (2003). La educación patrimonial. Teoría y práctica en el aula, el museo e internet. Gijón: Trea.

Fontal, 0. (2016). El patrimonio a través de la educación artística en la etapa de primaria. Arte, Individuo $\quad y \quad$ Sociedad,28(1), 105-120. Recuperado de https://revistas.ucm.es/index.php/ARIS/article/view/47683

Fontal, O., y Martínez, M. (2017). Evaluación de programas educativos sobre Patrimonio Cultural Inmaterial. Estudios pedagógicos (Valdivia), 43(4), 69-89. Recuperado de https://dialnet.unirioja.es/servlet/articulo?codigo $=6649893$

Fontal, O., y Marín-Cepeda, S. (2018). Nudos patrimoniales. Análisis de los vínculos de las personas con el patrimonio personal. Arte, individuo y sociedad, 30(3) 483-500. Recuperado de https://revistas.ucm.es/index.php/ARIS/article/view/57754

Funari, P. P. y Pinsky, J. (2003). Turismo e patrimônio cultural. São Paulo: Contexto.

Geovan, D., Baptista, L., y Cardozo, P. (2017). Educación, restauración y turismo: Una reflexión dialéctica aplicada a la Casa Sede de la Hacienda Forestal (Irati, Brasil). Estudios y perspectivas en turismo, 26(2), 441-460. Recuperado de https://dialnet.unirioja.es/servlet/articulo?codigo $=6327733$

Giacomasso, M. V., Mariano, M., y Conforti, M. E. (2014). Jóvenes resignificando patrimonios: análisis de una experiencia escolar en la ciudad de Olavarría. Espacios en Blanco-Serie Indagaciones, 24, 225-246. Recuperado de https://ri.conicet.gov.ar/handle/11336/9014

Gomes, A. (2000). Turismo cultural y política cultural urbana: posibilidades y divergencias. En Luis César Herrero (coord.), Turismo cultural: el patrimonio histórico como fuente de riqueza (pp.343-363). Valladolid: Fundación de Patrimonio Histórico de Castilla y León.

Gómez, M. D. C., Calaf, R. y Fontal, O. (2016). Diseño de un instrumento de análisis en recursos didácticos patrimoniales. Cadmo, 1, 63-80. Recuperado de http://uvadoc.uva.es/handle/10324/25825

González-Varas, I. (2015). Patrimonio cultural. Conceptos, debates y problemas. Madrid: Cátedra.

Grunberg, E. (2014). Educação patrimonial: Utilização dos bens culturais como recursos educacionais. Cadernos do Ceom, 14(12), 163-186. Recuperado de https://bell.unochapeco.edu.br/revistas/index.php/rcc/article/view/2133

Gutiérrez, R. (2012). Educación artística y comunicación del patrimonio. Arte, individuo y sociedad,24(2), 283-299. Recuperado de https://revistas.ucm.es/index.php/ARIS/article/view/39035

Hall, D., Roberts, L., y Mitchell, M. (2017). New directions in rural tourism. London: Routledge. Hernández, M. (2002). Algoritmos genéticos y predicción de la composición de la demanda turística. Tesis Doctoral. Recuperado de https://riull.ull.es/xmlui/handle/915/9978 
Hernàndez i Martí, G. M. (2008). Un zombi de la modernidad: el patrimonio cultural y sus límites. La Torre del Virrey: revista de estudios culturales, 5, 27-38. Recuperado de https://dialnet.unirioja.es/servlet/articulo?codigo $=2598698$

Hernández, A. M., Moroño, A., y Guillén, R. (2021). La educación patrimonial como pilar fundamental en el desarrollo del sector turístico. En F. J. Cambero, A. Díaz, Y. Fernández, M. Sánchez-Oro y J. Estepa (coords.). Recursos turísticos, territorio y sociedad en Extremadura: catalogación, nuevos usos y perspectivas (pp. 365-384). Cáceres: Universidad de Extremadura

INE. (2021). Movimientos turísticos en fronteras 2019. Madrid: Instituto Nacional de Estadística. Recuperado de fronterashttps://www.ine.es/dyngs/INEbase/es/operacion.htm?c=Estadistica_C\&cid=12 $54736176996 \&$ menu=ultiDatos\&idp $=1254735576863$

INE. (2021). Movimientos turísticos en fronteras 2020. Madrid: Instituto Nacional de Estadística. Recuperado de fronterashttps://www.ine.es/dyngs/INEbase/es/operacion.htm?c=Estadistica_C\&cid=12 $54736176996 \&$ menu $=u l t i D a t o s \& i d p=1254735576863$

Ishihara-Brito, R., y Rodríguez, P. B. (2012). Reliquias, artefactos y herramientas educativas: conservación del patrimonio cultural por la educación pública en el museo y centro educativo Kumatzim Jay, Tecpán Guatemala, Chimaltenango. Chungará (Arica), 44(3), 445453.

Recuperado

de

https://www.redalyc.org/articulo.oa?id=32623839007\&idp=1\&cid=91426

Leno, F. (1993). Técnicas de evaluación del potencial turístico. Madrid: Ministerio de Industria Comercio y Turismo.

López, D. (2008). Factores de localización espacial del turismo rural. En Juan Ignacio Pulido (coord.). El turismo rural. Estructura económica y configuración territorial en España, (pp. 155-176). Síntesis: Madrid.

Martín, B. (2003). Nuevos turistas en busca de un nuevo producto: El patrimonio cultural. PASOS. Revista de Turismo y Patrimonio Cultural, 1(2), 155-160. Recuperado de https://www.redalyc.org/articulo.oa?id=88110204

Mendioroz-Lacambra, A. (2016). Propuesta formativa en el grado de maestro de Educación Infantil, para trabajar el método de investigación histórica en el aula. Arte, Individuo y Sociedad, 28(3), 399-414. Recuperado de https://revistas.ucm.es > index.php > ARIS > article $>$ viewFile

Meunier, A., y Poirier-Vannier, E. (2017). La exposición en los museos de sitio como herramienta de sensibilización al patrimonio arqueológico. Estudios pedagógicos (Valdivia), 43(4), 305318. Recuperado de https://dialnet.unirioja.es/servlet/articulo?codigo $=6649896$

Ministerio de Cultura y Deporte. (2021). Base de datos de bienes muebles. Recuperado de https://www.culturaydeporte.gob.es/bienes/buscarBienesMuebles.do

Miralles, P., Gómez, C. J., y Rodríguez, R. (2017). Patrimonio, competencias históricas y metodologías activas de aprendizaje: Un análisis de las opiniones de los docentes en 
formación en España e Inglaterra. Estudios pedagógicos (Valdivia),43(4), 161-184. Recuperado de https://dialnet.unirioja.es/servlet/articulo?codigo=6649882

Moncada, J. A., Aranguren, J., y Pellegrini, N. (2016). Los senderos transitados: Una mirada al estado del arte de la interpretación ambiental en Venezuela entre 2000 y 2015. Revista de Investigación, $\quad 40(88), \quad 15-37 . \quad$ Recuperado de https://dialnet.unirioja.es/servlet/articulo?codigo $=6326452$

Morales, J. (2001). Guía práctica para la interpretación del patrimonio: el arte de acercar el legado natural y cultural al público visitante. Sevilla: Junta de Andalucía.

Orduna, G., y Urpí, C. (2010). Turismo cultural como experiencia educativa de ocio. Polis. Revista Latinoamericana, 9(26), 1-20. Recuperado de https://journals.openedition.org/polis/102

Otto, A. (2007). ¿Sueño o pesadilla en Mallorca? Un proyecto pedagógico interdisciplinario adecuado a la cultura de ocio y diversión. PASOS. Revista de Turismo y Patrimonio Cultural, 5(2), 225-242. Recuperado de https://www.redalyc.org/articulo.oa?id=88150207

Pellegrini, N. (2009). Sendero de interpretación ambiental en el bosque de la Universidad Simón Bolívar. SAPIENS, 10(2), 47-68. Recuperado de https://www.redalyc.org/articulo.oa?id=41021266003

Pinto, H., y Zarbato, J. (2017). Construyendo un aprendizaje significativo a través del patrimonio local: prácticas de Educación patrimonial en Portugal y Brasil. Estudios pedagógicos (Valdivia), 43(4), 203-227. Recuperado de https://scielo.conicyt.cl/scielo.php?script=sci_abstract\&pid=S071807052017000400011\&lng=es\&nrm=i.p

Prats, L. (2006). La mercantilización del patrimonio: entre la economía turística y las representaciones identitarias. Revista ph, 58, 72-80. Recuperado de https://www.iaph.es/revistaph/index.php/revistaph/article/view/2176

Prats, L. (2011). La viabilidad turística del patrimonio. PASOS. Revista de turismo y patrimonio cultural, 9(2), 249-264. Recuperado de http://pasosonline.org/Publicados/9211/PS0211_03.pdf

Quintana, C., y Stagno, R. (2009). Patrimonio y turismo: la activación turística patrimonial de Purificación (Paysandú, Uruguay). PASOS. Revista de Turismo y Patrimonio Cultural, 7(2), 307-319. Recuperado de http://pasosonline.org/Publicados/7209/PS0209_12.pdf

Reyes, A. C., Guerra, E. A., y Quintero, J. M. (2017). Educación en gastronomía: su vínculo con la identidad cultural y el turismo. El periplo sustentable, 32, 1-22. Recuperado de https://dialnet.unirioja.es/servlet/articulo?codigo $=6050938$

Reyes, M., Olague, J. T., y Verján, R. (2018). Estrategia de gestión pública para un enoturismo sustentable a partir de la percepción de problemas ambientales: el Valle de Guadalupe (México). Estudios y perspectivas en turismo, 27(2), 375-389. Recuperado de https://www.redalyc.org/articulo.oa?id=180755394011

Sánchez-Peña, L. (2012). Alcances y límites de los métodos de análisis espacial para el estudio de la pobreza urbana. Papeles de Población, 18(272), 147-179. Recuperado de https://www.redalyc.org/articulo.oa?id=11223536007 
Teruel, M. D. (2016). Eficiencia comunicativa de las Páginas Web en el caso de la gestión turística de los Sitios Patrimonio de la Humanidad en España. Boletín de la Asociación de Geógrafos Españoles, 71, 323-346. Recuperado de https://bage.agegeografia.es/ojs//index.php/bage/article/view/2285

Tilden, F. (2009), Interpreting our heritage. Chapel Hill: Univ of North Carolina Press.

Troncoso, C., y Almirón, A. (2005). Turismo y patrimonio. Hacia una relectura de sus relaciones. Aportes y Transferencias, 9(1), 56-74. Recuperado de https://www.redalyc.org/pdf/276/27690104.pdf

UNWTO. (2021). Sustainable Development of Tourism. Definición. Recuperado de https://www.unwto.org/es/desarrollo-sostenible

Valderrama, J. A., Meraz, L., Velázquez, G., y Flores, J. C. (2012). Rutas enológicas como estrategia de posicionamiento turístico para Baja California, México. Global Conference on Business and Finance Proceedings, (pp.1429-1432). Institute for Business \& Finance Research.

Vasko, A. (2018). Más allá de la arqueología académica: conversando con los guías comunitarios de Uaxactún. Estudios de cultura maya, 51, 129-150. Recuperado de https://dialnet.unirioja.es/servlet/articulo?codigo $=6533351$

World Heritage Centre (2017). Operational Guidelines for the Implementation of the World Heritage Convention. París: UNESCO, World Heritage Centre. Recuperado de https://whc.unesco.org/en/guidelines/

Ximena, M. (2018). Turismo y sitios arqueológicos en Las Islas Shetland del Sur, Antártida. PASOS. Revista de Turismo y Patrimonio Cultural, 16(1), 99-116. Recuperado de http://www.pasosonline.org/Publicados/16118/PS118_07.pdf 